\title{
Gender Norms, Sexuality and Post-socialist Identity: Does Migration Matter?
}

\author{
Irina Gewinner ${ }^{1,2}$ (ID
}

Published online: 23 January 2020

(c) The Author(s) 2020

\begin{abstract}
This article problematizes gender norms, sexuality and post-socialist individual cultural legacy by focusing on attitudes towards gendered sexual initiation and related family formation in migrant Russian-speaking women in Germany. It represents the results of a study that investigates whether and how norms of sexual maturity, adulthood and sexual behavior undergo a change or preservation in women after a migration episode and adjustment to a new cultural environment. By doing so, this piece of research scrutinizes the norms of (sexual) maturity, mostly associated with sexual debut and accompanied interpersonal experiences, common for individuals who underwent socialization in the (post-) socialist period and are now living in Germany. Drawing on primary data stemming from online discussions with Russian-speaking first generation migrant women in Germany, this study addresses not only individual cultural understandings of sexuality, adulthood and sexual behavior, but also gives implications on the revival of 'traditional values' in post-socialist contexts. This research, thus, contributes to the debate on how far cultural norms can transform through a change of the geographical context.
\end{abstract}

Keywords Gender and sexuality norms · Post-socialism $\cdot$ Russian-speaking migrant women · Germany

\section{Introduction}

In recent decades, studies on migration have proliferated, due in part to the increased flows of migrants, and especially women among them (OECD.Stat 2019), and the reconsideration of analytical frameworks regarding migration policies. While one of

Irina Gewinner

irina.gewinner@uni.lu; i.gewinner@ish.uni-hannover.de

1 Institute of Education and Society, Maison des Sciences Humaines, University of Luxembourg, 11, Porte des Sciences, 4366 Esch-sur-Alzette, Luxembourg

2 Institute of Sociology, Leibniz Universität Hannover, Schneiderberg 50, 30167 Hannover, Germany 
the strongest research avenues concerns the reconceptualization of the interconnection of nation state, migration, citizenship and justice (Bauböck and Rundell 2018; Bosworth et al. 2018), studies on cultural changes in migrants and pluralization of receiving societies through migration processes have been somewhat sidelined. At the same time, considerable numbers of individuals raise their children in cultural environments rather different from those they grew up in themselves, which entails the potential for additional tensions and misunderstandings between parents and children (Giguère et al. 2010; Renzaho et al. 2011; Rogers-Sirin et al. 2014). Accounting for cultural values as a powerful determinant of assimilation and simultaneously an arena for intergenerational conflict, this study sheds light on aspects of individual agency and social norms associated with attitudes towards sexual initiation and sexuality after migration in Russian-speaking women living in Germany.

A considerable body of research on social and cultural norms focuses on countries with postmodern culture in relation to sexuality, with processes of individualization and detraditionalization foregrounded in most studies (Ahmadi 2003; Hirsch 2003; Gonzáles-López 2005). Cultural norms imported from Eastern European to receiving countries have been rarely spotlighted so far, apart from noteworthy exceptions (Evans et al. 2009; Röder and Lubbers 2015; Mole et al. 2017). This is in part due to the scarcity of data: large-scale surveys allow analysis of norms regarding sexuality and their changeability in various societies, yet Russian-speaking migrants rarely feature in these data and are, thus, difficult to access.

The case of Russian-speaking women in Germany, which represents the focus of this study, is rather peculiar: this group of people is diverse along the axes of social inequality, native language, country of origin, duration of stay in Germany and immigration background. Moreover, many of them experienced up- or downward status mobility or even "contradictory class mobility" (Parreñas 2015) with possible effects on their attitudes and values (Qi 2016; Kalmijn and Kraaykamp 2018). While it can be assumed that Russian language and certain cultural traditions share a common denominator, the heterogeneity of women should be kept in mind. What they might have shared are social norms about sexuality, usually placed into the private sphere, but in recent decades, intimacy and sexuality have been contested publicly by various actors, such as the state or the Russian Orthodox Church (Attwood and Issuopova 2018; Gradskova and Morell 2018). According to studies, sexual initiation age in post-socialist countries dropped to 16-18 in the 1990s (Lunin et al. 1995; Golod 1996). Other studies indicate the age of 16.8 (World Health Organization 2007; Kuchma and Sokolova 2017). The norms are supposed to be transferred by migrants across borders and influence their post-migration lives and behaviors. Sexual resocialization of one of the biggest migrant groups has been under-researched in this context so far.

Germany, in contrast, represents an arena of openly lived and discussed sexuality, yet with a certain mix of values and gender ideologies resulting from reunification (Sharp 2004: 349; Grunow et al. 2018). While West German social policies have been supporting the conservative male breadwinner model and family values for a quite a long time, which resulted in a male dominance in sexuality, East Germany celebrated women's economic independence and, as a consequence, a "disappearance of the double moral standard for men and women" (Schnabel 1991: 27). 
Indeed, two Germanies diverged with regard to gender and sexual relations (Rohnstock 1996), and these cultural values and patterns of behavior are unlikely to disappear overnight. This can be indirectly seen in statistics on sexual initiation. Studies provide inconsistent information on the average age of sexual initiation in Germany, and some report on the earlier debut age of women in West Germany (Bozon and Kontula 2014). While some of these studies specify 16 years (Bozon and Kontula 2014), others state 17.2 years (BRAVO 2009; Delisle 2015; Berliner Kurier 2017), yet most agree that teenage sexual relationships can be characterized as relatively gender equal (Bozon and Kontula 2014).

This article poses the question: What are the attitudes of Russian-speaking firstgeneration migrant women towards sexual initiation, are they gendered and do these modify after migration to Germany? The study focuses solely on women, thus foregrounding gender and the complexity of intersectional processes underlying women's histories and individual beliefs on sexuality. By highlighting the views of migrant women on sexual initiation, first sexual experiences, and early relationships, this study utilizes data from online discussions in a closed virtual space accessible only to women, which reduces the level of potential public control associated with the topic. The study, therefore, seeks to contribute to the bulk of knowledge on the fluidity or persistence of social norms associated with gender and sexuality, framed by the change in geographical contexts on the individual level, and accompanying lived experiences in a new social and gender order.

\section{Socialist Policies and Shaping Individual Beliefs on Sexuality}

Past research has identified a link between socialist state demographic policy and individual sexual behavior (David 1982; Hilevych and Sato 2018; Ignaciuk 2019). This association has been found to shape the gender identities of several generations of Soviet women (Rotkirch 2000; Zdravomyslova 2005; Temkina and Zdravomyslova 2015): the Soviet 'silent generation' (born 1920-1945), and the late Soviet 'generation of personalization' (birth years 1945-1965). Knowledge of the postsocialist 'generation of articulation' (born 1970-1987) is based on studies of middle-class urban women and is not exhaustive (Rotkirch 2000; Zdravomyslova 2003; Temkina 2009; Issoupova 2012). The formative sexual years of the first two fell into the period of the socialist era, which allows us to mark them as socialist generations. The third cohort experienced sexual socialization in the years before and after Perestroika and the fall of communism, which makes it a post-socialist generation.

\section{The Soviet Silent Generation}

The Soviet silent generation was mostly socialized under a unique mixture of policies of pronatalism and abortion legislation. Since issues of sexuality and sexual behavior were hardly addressed in their own right, insufficient knowledge about sexuality still resulted in women's consolidation of sexual and reproductive behavior. The sphere of lived sexuality existed within official marriage, with male partners 
who often dominated the initiation of sexual contacts. Due to the substantial lack of information regarding sexuality and sex education, women of the silent generation knew very little about sexual pleasure and rarely searched for it purposefully (Rotkirch 2000; Temkina and Zdravomyslova 2015). Overall, this generation can be characterized by sexual inequalities between men and women, with lower status attached to women's desires, practices, and spheres of competence, and rather traditional sexual practices against the background of publicly equalized gender relations (Haavio-Mannila and Rotkirch 2000).

\section{Generation of Personalization}

As early as the 1960s, attempts to introduce the first features of sex education and gain control over childbirth took place in the form of the medicalization of the public discourse (Hilevych and Sato 2018), yet policy discussions avoided the verbalization of sex and sexuality. While the state rhetoric continued to try to address women and show them models of proper social behavior, the factual sexual revolution was already underway. The age of sexual initiation lowered gradually (Haavio-Mannila and Rotkirch 2010) and pre-marital and extra-marital sexual interactions became accepted more broadly (Kon 2011). Love and friendship became the main reasons for sexual intercourse, with the first child usually called "the fruit of love" (Rotkirch and Kesseli 2010: 277). Although the public significance of the official marriage remained, the acceptance of pre-marital relationships and cohabitation increased.

Past research revealed a change in the norms of female sexuality and a shift to its separation from reproductive behavior (Temkina 2009). Yet, norms of sexuality still remained polarized, as the persistence in male and female spheres of competence and the double standard in sexual relations endured. This is especially true for pre-marital sexual experience: attitudes towards them remain persistently gendered and demonstrate a considerably higher tolerance towards sexually active men than women, the latter looked upon more negatively (Bocharova 1994; Haavio-Mannila and Kontula 2003).

\section{Generation of Articulation}

Temkina (2009: 37) identifies a gendered stage of the sexual revolution in the postsocialist space by highlighting the rationalization of sexual behavior, especially among women. Here, she differentiates between the cohorts born in the 1970s and 1980s, since the formative sexual years of the former occurred during perestroika and, of the latter, in the early 2000s, the years of relative stabilization. Common for both cohorts is the age of sexual initiation which is similar to Western countries, growing acceptance of premarital sexual behavior, and increased understanding of independent-i.e. detached from reproduction-sexuality as desire and pleasure. Although not ubiquitous, orientation towards egalitarian partnerships is particularly pronounced in younger generations born in the 1980s, which points at liberalization of attitudes and particularly women's behavior especially in urban areas. 
At the same time, practices of sexuality remain highly gendered and polarized (Temkina 2009: 39), which implicates a certain path of dependency in the division of spheres of competence and habits in everyday life. The latter remain separated, which aligns with the traditional division of paid and unpaid labor: men are expected to act as breadwinners, women are responsible for homemaking and child rearing. Attwood and Issuopova (2018: 153) reason that, in this regard, although women have more choices when compared to Soviet times, the division of family roles remains very conservative. It is, therefore, not surprising that one of the identities of the post-socialist generation is based on the instrumental sexual script (Temkina and Zdravomyslova 2015). It includes sex as a means of status attainment, economic exchange and service, with sexual attractiveness being the main issue in which to invest. Simultaneously, previous research identified a hedonistic understanding of sexuality, the second post-socialist sexual identity (Temkina and Zdravomyslova 2015). It rests on the awareness of sex as a fundamental component and integral part of a successful life, entailing not only informed handling with contraceptives, but also responsible sexual practices and egalitarian partnerships.

All in all, trends of liberalization of sexuality against the background of gender polarization and somewhat stereotyped sexual culture display highly ambivalent individual attitudes and sexual practices in the post-socialist space. It can be hypothesized that migrant women of different generations would transfer the cultural values in the host country, but utilize different notions and understandings of sexuality depending on the context and their own experiences. Moreover, considering crucial structural characteristics, such as place of origin, level of education and generational affiliation, might help to shed light on the views and attitudes of Russian-speaking migrant women in Germany, thus providing a dynamic picture of post-socialist migrant sexual culture.

\section{Data and Methods}

\section{Data Collection Procedure and Ethical Issues}

This study utilizes a netnographic approach (Kozinets 2010) to analyze the sexual resocialization of Russian-speaking migrants in Germany. There are several reasons for this choice: firstly, migrants extensively use the Internet and especially Russianspeaking Facebook groups to communicate with other migrants, to ask for advice or just to talk and exchange ideas. This is also the case due to varying German language proficiency in migrant women: those who came as dependents to/with their husbands and have been living in Germany for a short time are especially in need of communication or help in Russian, at least online. Additionally, according to the previous research, (Russian-speaking) migrants are likely to believe that fellow citizens, defined by the same language and collective memory, would understand and help them better than natives (Dekker and Engbersen 2014; Borkert et al. 2018).

Secondly, online communication in closed Facebook groups of interests gives an impression of anonymity and security in expressing people's own opinions. This is especially true for topics connected with intimacy and sexuality, as in 
face-to-face interviews or discussions, women would rather resort to social expectations in their answers and personal life histories than disclose detailed information on their own experiences. Sharing attitudes and personal life experiences with other women on a voluntary basis gives deeper insights into the mindset of migrants without personalization and interfering with their privacy. For empirical analysis, the study chose a closed but active group with about 28,000 members, where women discuss a broad spectrum of topics often related to personal relationships, intimacy and sex. The possibility for a topic starter to appear anonymously in the community considerably reduced the barrier to addressing any specific problem as a subject to discussion.

Thirdly, closed Facebook groups for women not only attract individuals with diverse backgrounds, but also membership is based on the fact of having a direct relation to Germany and/or living there. Therefore, women of different ages, social origin, levels of education and duration of stay in Germany can be found there without difficulty. Those who left comments and expressed personal opinions under topics related to sexuality represented the sample of the study, and their answers have been analyzed qualitatively.

For reasons of topic sensitivity and ethical considerations, the empirical exploration opted for the non-interventional online approach to minimize the degree of influence on participants (Kozinets 2006, 2010; Hine 2017). Thus, comments about the group's discussants have been observed without being questioned or answered back. The author did not identify herself as a researcher to avoid creating an artificial atmosphere or endangering the course of a discussion. Informed consent was not possible, not only due to content-related issues, but also technically, since the researcher reconstructed 150 women's histories, related to sexual initiation and first relationships, by bringing together several comments the women left in different parts of the online discussion. Yet, to ensure full anonymity and minimize risks for human subjects (Bruckman 2002; Kozinets 2010), the author anonymized the names of the latter by providing each discussant with a number and translated the opinions from Russian into English to ensure the impossibility of tracking them down. In the second step, translated real comments have been paraphrased according to the guidelines of the European Commission on 'Ethics in Social Science and Humanities' (European Commission 2018).

This study analyzed the change of individual cultural norms and understandings of sexuality, adulthood and the role of sex education in migrant women particularly focusing on three dimensions: (gendered) sexual initiation, first sexual relationships, and readiness to have a child. All these aspects of sexual behavior are tightly interconnected due to the close link between sexual education and sexual practices of individuals. To grasp the change in or persistence of the attitudes, community members were asked through a topic starter to provide an opinion on a real situation described as a starting point for a discussion: a 15-year-old girl, the daughter of an anonymized topic starter, is in a relationship with an 18-year-old boy and stays overnight at the girl's parents' house, and they all have breakfast together the next morning. The community members were invited to estimate whether such a situation is normal, opine whether a girl should be allowed to stay with a boy overnight and to consider their own experiences of such 
scenarios. Additionally, the women in the online community were asked for advice about how the mother of the 15-year-old girl should behave in such a situation.

\section{Sample Description}

Overall, the topic under study generated 1100 online comments. Valid answers from 150 women have been identified, reconstructed by collecting single comments throughout the discussion, noted down verbatim and evaluated using deductive categories that helped analyze the persistence or fluidity of cultural norms pertinent to sexuality. Additionally, labelling the most frequent words allowed for the discovery of important notions and their implicit interconnections, significant for migrant women. In that way, it was possible to compare individuals' own experiences in the past with their attitudes to the same issues in the present. Moreover, this method enabled the researcher to disclose any double standards behind the problematic of sexual initiation and related issues that are closely interlinked with first sexual experiences, and prevent social desirability in the answers of the discussants by making them think over modes of behavior in a similar situation with their own children. In addition, respective contributors have been screened online to obtain information about their generational affiliation, place of origin (country of the former Soviet Union), settlement type (urban or rural), level of education and duration of stay in Germany. These details helped to determine any association between their beliefs and structural factors, and enrich the findings of the study, thus overcoming limitations of the previous research. The overview is seen in Table 1.

The sample contains information on several cohorts of Russian-speaking women living in Germany. Understandably, the silent generation (born 1920-1945) could not be included in the sample, since its representatives are unlikely to use social media on a daily basis. The generation of personalization is represented by 12 women born in the 1960s. The sample provides the richest information on the generation of articulation and allows differentiating particular cohorts: born in the 1970s (52 individuals) and in the 1980s (73 persons). This study advances the research by integrating the youngest sexually active cohort who were born in the 1990s. In the sample, this cohort is represented by 13 women. Previous studies lack information on attitudes regarding sexual initiation and the first relationships of this young cohort, especially among women migrants.

The majority of women in the sample are married, some live in a stable partnership, and most have at least one child, which is especially important for the topic of interest within this study. Comparing women's own experiences with opinions pertinent to their children's sexual behavior is crucial for identifying possible liberalization of values related to sexual initiation and mid-adolescent sexual relationships.

\section{Findings}

To make conclusions about post-migratory persistence or fluidity of individual beliefs pertinent to sexual initiation and first sexual relationships, the author analyzed opinions by separating the birth cohorts. In that way, it was possible to 


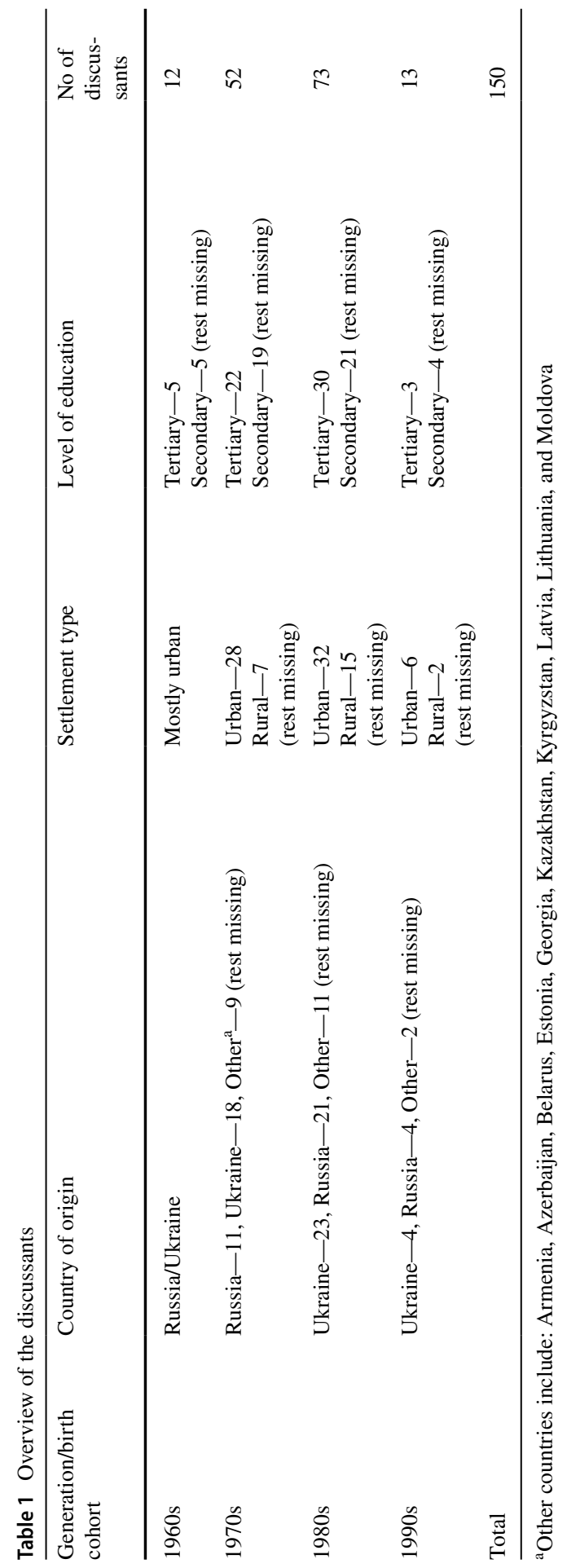


scrutinize the attitudes of women related to sexual initiation and shed light on the extent of change occurring in the attitudes of Russian-speaking women in Germany. Additionally, incorporating personal stories of the discussants (if provided) and verifying these through the structural characteristics helped diversify the picture. At the same time, some common topics appeared concurrently in different parts of the discussion irrespective of the cohort. They included not only attitudes to sexual initiation in its own right but embraced also adjacent topics, such as responsibility, own experiences, and societal double standards. This is why the next sections are grouped based on the common themes emerging throughout the discussion.

Interestingly, attitudes towards sexual initiation and sexual relationships with peers, voiced by women from different birth cohorts, were noticeably ambivalent. The first observed trend showed increasing tolerance for teenage sexual relationships with each successive cohort. While elder women with a migration background expressed mostly negative opinions with regard to this issue, their younger counterparts had more egalitarian viewpoints. There are grounds to believe that the cohort of women born in the 1960s migrated to Germany in the 1990s and have had the longest duration of stay there. This was evident from the life stories they shared during the discussion and the way they described their children's first sexual relationships. According to them, women with a migration background experienced tensions with their children due to the diverging values and contexts in which they were socialized:

I live here 28 years now, but I've never seen teenagers bringing their partners to parents' homes. (born 1960s, rural Ukraine, secondary education, 28 years in Germany)

My son started bringing home some girls after parties, I didn't like it and he lives separately since he has turned 18. (born 1960s, urban Russia, over 10 years in Germany)

The second identified trend showed that despite overall increasing tolerance towards openly lived sexual initiation in discussants' children and first sexual partnerships, it was not distinctly linear. The cohort born in the 1970s still pronounced more negative attitudes, although egalitarian voices could be recognized along with judgemental ones. The cohort born in the 1980s expressed divided opinions with a growing number of women without a clear standpoint. The cohort born in the 1990s demonstrated ambivalent opinions as well, yet egalitarian viewpoints dominated the discussion. The diversity in attitudes towards sexual initiation and unsilenced sexuality in mid-adolescent age indirectly manifested itself also through the discussants' origin: contributors coming from Russia and Ukraine voiced somewhat more liberal opinions, yet these women outnumbered others in the sample.

\section{Responsibility and Control}

Many discussants implicitly equated sexual initiation with achieved and perceived sexual maturity, being in line with individual mental maturity, or ability to assess the consequences of their own actions. To some extent, they communicated this 
through the young girl's own understanding of the self as an adult and linked sexual initiation and sex in middle adolescent age with individual ability to make and take responsibility for their own decisions. Yet, certain differences could be observed depending on the generational affiliation of migrant women. While representatives of the generation of personalization unanimously attributed early sex to lack of good education and manners, the opinions of their younger counterparts bifurcated:

Both my daughter and her boyfriend are 18. Yesterday, they were sitting in her room, but at $11 \mathrm{pm}$ I came in and said it was already late and he should go. I'm shy about this situation and I'm very conservative, but I just can't imagine what I should do... When relationships are more serious and children are older, then I would accept stays overnight and joint lunches. (born 1960s, urban Ukraine, tertiary education, about 4 years in Germany)

At 15 it is too early, only after coming of age. And parents should talk about the responsibility for the consequences. (born 1990s, urban Russia, secondary education, about 3 years in Germany)

When I was 15, I was engaged in many activities, such as art school, sports, and school theatre, but at the same time, I was pretty much interested in boys, lost my virginity and generally had a lot of fun. (born 1990s, urban Russia, secondary education, over 10 years in Germany)

In the comments above, some contributors reflect their own experiences while expressing personal opinions regarding adolescent sexual relationships. It can be seen that the attitudes of the youngest cohort in the study towards sexual initiation and first sexual relationships have become more liberal and open. Simultaneously, the ambivalence of women's views mirrors the presence of multiple identities without a straightforward development from the discourse on virginity preservation to a discourse on gender equality. Throughout the cohorts, the word 'responsibility' was pronounced quite often, and it was more associated with unpleasant and unavoidable consequences. In that way, women in the discussion directly connected sex, which, according to their understanding, can be hardly practiced in a responsible way at the age of 15, with foreseeable pregnancy and the associated dilemma of whether or not to undertake an abortion.

This is hypocrisy! Children at 15 are not able to control their behavior and what they are doing. (born 1970s, urban Ukraine, tertiary education, about 3 years in Germany)

I think the girl does not understand that someone just uses her... Not having sex at the age of 15 demonstrates a normal responsible behavior. Adults should control themselves and make children do so. When I was 15, I didn't want to date anyone and didn't let anyone tell me stories about love... There is no need to have sex at 14-15 years. (born 1970s, urban Russia, tertiary education, over 10 years in Germany)

I wouldn't let the boy in. I remember I brought a boyfriend just because he had no place to go when I was 18. My granny grumbled the whole night that we would be so loud that no one would sleep... Children at 15 do not earn anything, but already want to f...ck like adults, pretending they are as 
mature as we are. I believe, they are not adults, since they are unable to bear any responsibility. (born 1980s, rural Ukraine, secondary education, about 2 years in Germany)

I spent my first earned money for a doll when I was 15! What kind of kids do we have now?? (born 1990s, urban Baltic country, secondary education, about 5 years in Germany)

The logical chain 'sex-consequences-responsibility' in the understandings of sexual maturity in Russian-speaking women in Germany is particularly worth looking at here. During the course of the online discussion, it became apparent that the definition of responsibility consists not simply of being able to raise a child after a potential pregnancy, but also the ability to earn a means of living and start a family, which includes official marriage. Consistent with previous research, this study finds that for Russian-speaking women, sexual initiation is imaginable within a steady relationship, but hardly thinkable as an uncommitted experience (Bozon and Kontula 2014). The direct link between adolescent sex, unwanted pregnancy and marriage is a subtle, yet very prominent, cultural pattern many women shared and some pronounced openly. Moreover, this responsibility was generally expected from men, or in the case of the discussion subject, the young partner of the girl under consideration. Women, or the daughter of the topic starter, were anticipated to take over a role of the mother, or caregiver, instead. The moral legitimacy of sex is thus communicated through the expectation of marriage, and sex at an early age can only be justified if the male partner is going to marry the girl. This cultural pattern, although not always addressing only daughters, again reveals the polarized sexuality norms that go hand in hand with divided spheres of responsibility, together pointing at traditional femininity, as Temkina and Zdravomyslova (2015) describe it. This type of identity is particularly identifiable for the cohort born in the 1980s:

This teenage couple should wait until they can legally marry. I would allow them if they can't wait to have sex any longer. (born 1980s, rural Russia, secondary education, over 10 years in Germany)

My children will bring only their wives or husbands into our home. (born 1980s, urban Russia, tertiary education, about 6 years in Germany)

Sexual initiation and relationship based on 'real love' were pronounced within the cohort born in the 1970s. Women justified early teenage sexual interactions by explaining that sex would bring a couple to a new level of relationship and make young people feel attached to each other. This was surprising since the sexual script based on friendship and romance was previously found to be characteristic for the generation of personalization. In the sample, this point of view was shared by women affiliated with the generation of articulation, originating from both urban and rural settlement types and with different levels of education:

My daughters are 15 and although they haven't kept their promise to wait until 16, I'm happy they did it out of first love and had sex with their first stable partners. Their relationships entered the next stage, they care for each 
other and feel like couples. (born 1970s, urban Baltic country, secondary education, about 4 years in Germany)

15 might be too early if I compare it with my own experience and norms, but I stand for love and partnership that young people should not hide. (born 1970s, urban Ukraine, tertiary education, over 10 years in Germany)

At this point, the data deliver an ambivalent picture of the attitudes of migrant women to sexual initiation and first sexual relationships. On one hand, a clear liberalization trend is discernible, with younger cohorts being generally more open to early teenage sexual interactions. On the other hand, there are some common cultural patterns that women of all birth cohorts share, irrespective of their place of origin and level of education, such as association of early sex with probable pregnancy or the importance of marriage as a symbol of responsibility and monogamy as was apparent for the Soviet silent generation. It is likely that these opinions reflect their own experiences, as discussed in the next section.

\section{Sex Education and Experiences}

It looked as though many Russian-speaking women were not willing to communicate openly with their children about sex. This can be explained either by the Soviet tradition of silenced and suppressed sexuality that most of the respondents might have experienced in their sexual formative years from their parents or by the shame some discussants expressed in relation to this issue. The contributors' retrospection to their own experiences points to the reproduction of attitudes to sex despite the change in the cultural environment by living in Germany.

In the course of the online discussion, it became apparent that talking with children about sex and its 'dangers' should ideally be a parental responsibility, something that eluded the discussants when they were adolescents themselves. Yet, only a few were ready to talk about it with their own children, mostly due to a deeply rooted feeling of shame and lack of motivation to overcome it. Not many women in the sample experienced sex education or at least trust and understanding on the part of their parents. As expected, most experiences regarding their first boyfriend, sexual experience and intimacy were overshadowed by apparently negative reactions, humiliation and extremely painful arguments with their own parents:

I experienced my first sex at 16, and all my friends had it at the same age. I was afraid my father would kill me... So what? It didn't change anything! I would support my daughter and value her trust. (born 1970s, urban Belarus, secondary education, over 10 years in Germany)

Since I experienced much of humiliation from parents about a boyfriend that I had at the age of 18 , I would now allow my daughter to stay overnight with her boyfriend and I would teach her how to use contraceptives... For my parents, it didn't matter I was 18, they didn't care and considered me a slut, we had major scandals... (born 1980s, urban Russia, tertiary education, over 10 years in Germany) 
I wasn't even allowed to bring my female friends and you ask about boyfriends! No way! (born 1990s, urban Ukraine, tertiary education, about 3 years in Germany)

Russian-speaking women from the Facebook group grew up in restrictive family relations with little space for individual sexual freedom, irrespective of their age when first sexual contact occurred. Their fathers' ways of treating them are especially striking, since these coined perceptions and modes of behavior for the rest of the women's lives and shaped not only their own relationships with partners, but also those of their children later on, as can be concluded based on the online discussions:

I'm against sex at such a young age. We were raised differently and could never even think of staying overnight together with partners-our parents would kill us! (born 1980s, rural Russia, secondary education, over 10 years in Germany)

I can't bring anyone into my parents' home, I won't even be able to bring my husband-I'll always be a little girl for my father. (born 1980s, urban Baltic country, tertiary education, about 5 years in Germany)

Although some discussants' viewpoints demonstrated a clear departure from their parents' restrictive practices, others inherited a negative attitude towards openly lived sexuality in teenagers, both again pointing at the ambivalence of social norms towards sexuality. The case of Russian-speaking women in Germany illustrates how restrictive parents and, particularly, the dictatorship of fathers creates a certain agency frame with far-reaching consequences, which is particularly interesting when taking into account the non-involvement of men in child-rearing processes throughout socialist times (Issoupova 2012). Indeed, this study detects gender differences in perception of sexual maturity: according to the online discussion, whereas men are extremely critical towards their daughters and their virginity, women show more diversified opinions:

Any man is unambiguously negative about this. At 15 , no discussion, no sex should take place, I agree here. At 17-18 this can look differently... (born 1960s, urban Russia, tertiary education, over 10 years in Germany)

A daughter of my neighbors brought her boyfriend home when she was $14 \ldots$ my husband was indignant! Now it's even worse: our own daughter is growing up, it's even more difficult to say how I'd behave. Actually, at 16 I won't forbid them to sleep at our home, but my husband... (born 1970s, urban Russia, tertiary education, over 10 years in Germany)

My daughter will be 15 soon, I'm afraid she will bring her boyfriend home... By the way, I got my son at 17... (born 1980s, urban Ukraine, tertiary education, over 10 years in Germany)

I don't have children yet, especially teenagers, but I remember being 15 myself. Back then, I was not willing to mix personal life and parents, so the first one who stayed overnight under the parental roof was my husband. (born 1990s, urban Ukraine, secondary education, about 5 years in Germany) 
Overall, discussants' own experiences in the past seemed to better determine women's attitudes towards sexual initiation and early sexual relationships than their migration episode. Life histories of sexual formative years turned out to have more impact on the opinions displayed in the online discussion. Here are some examples:

My parents always asked me to be open with them, to have sex on our territory, and not somewhere else. Same with me, I want to know all the friends and boyfriends of my children. 15 years is already a normal age for sex... When I had my first relationship at 14 , my parents took me to the gynecologist, and the fact that I did not get pregnant was not a miracle. (born 1970s, urban country in Central Asia, tertiary education, over 10 years in Germany)

Our parents tried to internalize in us since childhood that sex is something very bad, especially before the wedding or before 18. And many people are trying to apply the old principles in the new conditions. It does not work anymore. (born 1970s, urban Ukraine, tertiary education, over 10 years in Germany)

It was not only the age of women that predetermined their attitude towards sex at the age of 15, but more importantly, their level of education. Highly educated women demonstrated clear knowledge of issues associated with sexual education, and showed explicit trust in their children and readiness to help without rebuking or shaming them. Duration of stay in Germany did not seem to play a crucial role, since values transmitted during socialization had a stronger effect on women's present attitudes.

\section{Double Moral and Attitudes to Sexual Initiation and First Relationships}

A clear feature of the better-educated Russian-speaking women was also their ability to look outside the box and address the existing double standards in sexual education and sexual initiation of their children. The double moral detected in this study has several dimensions, which are consistent with previous research (Haavio-Mannila and Kontula 2003; Farvid et al. 2017), but also provides further insights into beliefs and attitudes imported by migrants from the former countries of the Soviet Union to Germany. Firstly, through the online discussion, the contributors showed double standards in their perceptions of sex regarding men and women. While Russian-speaking women were more likely to accept that their sons or some other young men had sex-in order to gain sexual experience, or to get access to financial or status resources through someone's daughters-and just excused men's behavior, they shamed young women and labelled them as accessible if they had sex an early age. As seen previously, such women were regarded as 'training material' for their sons, but could not be seriously regarded as future daughters-in-law. Strikingly, these discussants themselves were exposed to their husbands' anger as bad mothers who could not teach their daughters good manners in terms of sexual abstinence and humility:

My husband would kick me out of the house together with my daughter and her boyfriend. And not only when she is 15 , he would also do it when she would be 20 or 25 . It's part of our traditions and customs - a mother is respon- 
sible for a girl. (born 1970s, urban country in Caucasus, secondary education, over 10 years in Germany)

I have a daughter myself, if she even stutters about bringing a boy to stay overnight, my husband will be the first to kick the boy down the ladder, and then he will blame me for not having raised the daughter properly. (born 1980s, rural Ukraine, tertiary education, over 10 years in Germany)

As seen, firstly, women's opinions are dependent on those of their husbands. Secondly, women tended to accept their own sexual initiation and experience, but negatively connoted similar behavior of other women. For instance, some discussants reported that they gave birth to their children at 17, but at the same time, perceived sex under the age of 18 as unacceptable for decent women. Thirdly, the peculiar situation that served as a basis for the discussion, disclosed women's understanding of being adult and how women claimed their rights for demonstrating it. In that way, they juxtaposed themselves as owners of their homes, in which they believed they were able to do anything in order to validate their superiority towards children. Children, although already close to coming of age, had to follow parents' rules without questioning them:

In the discussion about having sex when your children are in the apartment, many wrote: "so what?" And now when we talk about sex of our children when you are in the next room-the same people say "never ever"... Double standards? (born 1980s, urban Russia, tertiary education, 4 years in Germany)

Fourthly, one of the most striking double standards revealed through analysis of the discussion was associated with pleasure on the one hand and responsibility on the other. Many Russian-speaking women in this study directly connected both without dividing them. Thus, they equated sex with an act of conceiving and biological reproduction, but not something detached from that, such as pleasure, a burst of emotions or hedonism. In that manner, the linkage between openly lived sexuality in a parents' residence and negative experiences, especially for (young) women, would be perpetuated through parents' control of young people. This would not allow a girl to relax and be satisfied through sex; thus, only a boy would achieve sexual satisfaction, not a girl, since she would need to mind her breath and emotions:

My husband and his friend told me, it was very uncomfortable for them back then to bring girls and have sex with them while their parents were at home. Their German girlfriends were often offended because of that... they behaved generally more liberally, even allowed themselves to make loud noises without thinking about parents. No matter where they met - at boys' or girls' places. (born 1980s, urban Russia, tertiary education, about 6 years in Germany)

Only a few discussants, mostly those defending sexuality for pleasure, noted that parents who want control are selfish and hardly think about the lesson taught to their own daughters. Encouraging sex at home serves the convenience and satisfaction of men, not women. This would only further cause prejudices in girls and develop an odd attitude towards sex. Ultimately, that would lead to the extraordinary situation in which adult women do not even know that sex can be satisfying for women. These 
contributors argued that sex is an integral part of life, and expressed an opinion that women who prohibit sex and feel ashamed while even mentioning it are just afraid of not having conveyed their rigorous views on pleasure and responsibility to their children.

\section{Discussion and Conclusion}

This study aimed to conceptualize individual understandings of sexual maturity and attitudes towards sexual behavior in the context of migration. Focusing on Russianspeaking women living in Germany, it has contributed to a body of knowledge that deals with change or preservation of cultural norms after a migration episode, and more generally, addressed the pluralization of gender norms in societies through migration. In contrast to previous research, this study did not examine women's own sexual practices to protect women's privacy, keeping in mind the ethical aspects of this issue. Instead, it followed a subtler approach and put a topic of sexual initiation and sex at a mid-adolescent age up for discussion on Facebook. By doing so, it sought to obtain insights into the post-migratory post-socialist accounts on sex that still remain under-researched. Scrutinizing the opinions expressed while answering the question on the sexual behavior of (their) children and its 'proper' forms gained not only reliable data on migrants' attitudes towards sex and their changes across time and space, but also retrospective information on women's own sexual experiences, sex education, and associated beliefs.

The analysis shed light on individual views on sexual initiation, first sexual experiences and teenage sexual interactions, all three dimensions being interconnected. Additional categories under inquiry, such as discussants' age, country of origin, type of settlement, level of education and duration of stay in Germany, enriched the study and provided more nuanced results on the research topic. This uncovered not only generational differences, but also persisting double standards in perceptions of (gendered) sexual initiation and sexual behavior, contrasting for young men and women. The findings showed that with every successive birth cohort, understandings of sexual practices in Russian-speaking migrant women become more liberalized, yet this is unlikely to be the result of migration, but an inherent component of women's identity that has been shaped during sexual formative years. Simultaneously, there is a high degree of variation and ambivalence across the cohorts. Clearly, higher levels of education are conducive to more tolerant attitudes towards sexual initiation and unconcealed teenage sexual interactions.

In summary, an overview of single birth cohorts of migrants might be useful. Representatives of the generation of personalization, born in the 1960s, mostly had a significant gap in sex education, restrictive control on the part of the state and parents and demonstrated rather negative attitudes towards sexual initiation and sexual relationships in mid-adolescent age. The interdependency of both love and sex demonstrated a peculiar meaning of sex and construction of sexuality among women born in the 1970 s, with sex being justified through love and serious intentions for the future as a married couple. Those born in the 1980s provided very diversified opinions towards sexuality among teenagers. To a certain 
extent, they did not overcome double standards and overall were only partially open to the norms of sexual behavior prevailing in Germany. The cohort born in the 1990s demonstrated the highest level of tolerance towards unsilenced sexuality in mid-adolescent age, but also here, a split of opinions on teenage sex-egalitarian and traditional opinions-was striking.

Advancing research on cultural resocialization of migrants and sexuality, this study has extended the knowledge about middle class urban Russian women and provided a broader picture on women originating from different countries of the former Soviet Union. This has helped to draw a more extensive image of (post-) socialist attitudes towards gendered sexual initiation and openly lived teenage relationships. By doing so, this study has addressed cultural identities and commonalities pertinent to women of several birth cohorts. Moreover, it is the first to encompass the youngest sexually active cohort born in the 1990s and has found divided opinions regarding teenage practices of sexuality, with liberalization trends and pluralist sexuality being particularly detectable for urban better educated young women.

The study challenges previous research that showed how individual practices and notions towards sex transform and detraditionalize after a migration episode to countries that are founded on individualism (Ahmadi 2003; Evans et al. 2009). The case of Russian-speaking women in Germany shows that their cultural understandings of sexual initiation and attitudes towards openly lived sexual interactions are gendered and do not considerably modify after migration. Women expressed ambivalent opinions throughout the birth cohorts and tended to accept openly lived mid-adolescent sexuality only within a stable relationship.

Although it could be shown that the duration of stay in Germany might influence socialized attitudes to some extent, it should be cautioned that due to the complexity of the sample, much information on Russian-speaking women was missing. Because of the nature of the research method, no data on the social status of women and its change after migration could be obtained. Future research should consider including such information and analyzing whether these attitudes are being enhanced by the German welfare state that supports families as an integral and basic part of the German society, or whether other mechanisms have impact on the views on sexuality in migrants. Additionally, it could be investigated whether natural aging processes and significant life events have an impact on persistence or fluidity of notions on sexual initiation and unsilenced mid-adolescent sexual interactions.

Acknowledgements Open Access funding provided by Projekt DEAL.

\section{Compliance with Ethical Standards}

Conflict of interest The author declares that she has no conflict of interest.

Ethical Approval All procedures performed in studies involving human participants were in accordance with the ethical standards of the institutional and/or national research committee and with the $1964 \mathrm{Hel}-$ sinki declaration and its later amendments or comparable ethical standards.

Informed Consent Informed consent was not obtained since the analysis was based on observation without direct interaction. Data were fully anonymized, thus making it impossible to identify any persons. 
Open Access This article is licensed under a Creative Commons Attribution 4.0 International License, which permits use, sharing, adaptation, distribution and reproduction in any medium or format, as long as you give appropriate credit to the original author(s) and the source, provide a link to the Creative Commons licence, and indicate if changes were made. The images or other third party material in this article are included in the article's Creative Commons licence, unless indicated otherwise in a credit line to the material. If material is not included in the article's Creative Commons licence and your intended use is not permitted by statutory regulation or exceeds the permitted use, you will need to obtain permission directly from the copyright holder. To view a copy of this licence, visit http://creativecommons.org/licen ses/by/4.0/.

\section{References}

Ahmadi, N. (2003). Migration challenges views on sexuality. Ethnic and Racial Studies, 26(4), 684-706.

Attwood, L., \& Issuopova, O. (2018). Choosing whether to have children: A netnographic study of women's attitudes towards childbirth and the family in post-Soviet Russia. In L. Attwood, E. Schimpfössl, \& M. Yusupova (Eds.), Gender and choice after socialism (pp. 133-158). Cham: Palgrave Macmillan.

Bauböck, R., \& Rundell, J. (Eds.). (2018). Blurred boundaries: Migration, ethnicity, citizenship. Abingdon: Routledge.

Berliner Kurier. (2017). Sex-Statistik. So alt sind die Deutschen bei ihrem ersten Mal. Retrieved November 13, 2019, from https://www.berliner-kurier.de/ratgeber/gesundheit/sex-statistik-so-alt-sind-diedeutschen-bei-ihrem-ersten-mal-26930614.

Bocharova, O. A. (1994). Seksual'naya svoboda: slova i dela. (Sexual freedom: Words and deeds). Chelovek, 5, 98-107. (in Russian).

Borkert, M., Fisher, K. E., \& Yafi, E. (2018). The best, the worst, and the hardest to find: How people, mobiles, and social media connect migrants in (to) Europe. Social Media + Society, 4(1), 2056305118764428.

Bosworth, M., Parmar, A., \& Vázquez, Y. (Eds.). (2018). Race, criminal justice, and migration control: Enforcing the boundaries of belonging. Oxford: Oxford University Press.

Bozon, M., \& Kontula, O. (2014). Sexual initiation and gender in Europe: A cross-cultural analysis of trends in the twentieth century. In M. Hubert, N. Bajos, \& T. Sandfort (Eds.), Sexual behaviour and HIV/AIDS in Europe: Comparisons of national surveys (p. 37). Abingdon: Routledge.

BRAVO. (2009). Dr.-Sommer-Studie. Liebe! Körper! Sexualität! München: Bauer Media Group.

Bruckman, A. (2002). Studying the amateur artist: A perspective on disguising data collected in human subjects research on the Internet. Ethics and Information Technology, 4(3), 217-231.

David, H. P. (1982). Eastern Europe: Pronatalist policies and private behavior. Population Bulletin, 36(6), $1-49$.

Dekker, R., \& Engbersen, G. (2014). How social media transform migrant networks and facilitate migration. Global Networks, 14(4), 401-418.

Delisle, B. (2015). Jugendsexualität zwischen medialer Darstellung und individuellem Erleben. Korasion, 29(2), 25-30.

European Commission. (2018). Ethics in social science and humanities. Retrieved November 13, 2019, from https://ec.europa.eu/research/participants/data/ref/h2020/other/hi/h2020_ethics-soc-sciencehumanities_en.pdf.

Evans, A. R., Parutis, V., Hart, G., Mercer, C., Gerry, C. J., Mole, R., et al. (2009). The sexual attitudes and lifestyles of London's Eastern Europeans (SALLEE Project): Design and methods. BMC Public Health, 9, 399.

Farvid, P., Braun, V., \& Rowney, C. (2017). 'No girl wants to be called a slut!': Women, heterosexual casual sex and the sexual double standard. Journal of Gender Studies, 26(5), 544-560.

Giguère, B., Lalonde, R., \& Lou, E. (2010). Living at the crossroads of cultural worlds: The experience of normative conflicts by second generation immigrant youth. Social and Personality Psychology Compass, 4(1), 14-29.

Golod, S. I. (1996). 20-j vek i tendentsii seksual 'nykh otnoshenij v Rossii (20th century and tendencies in sexual relations in Russia). Moscow: Aleteya. (in Russian). 
Gonzáles-López, G. (2005). Erotic journeys: Mexican immigrants and their sex lives. Berkeley, CA: University of California Press.

Gradskova, Y., \& Morell, I. A. (Eds.). (2018). Gendering postsocialism: Old legacies and new hierarchies. Abingdon: Routledge.

Grunow, D., Begall, K., \& Buchler, S. (2018). Gender ideologies in Europe: A multidimensional framework. Journal of Marriage and Family, 80(1), 42-60.

Haavio-Mannila, E., \& Kontula, O. (2003). Single and double sexual standards in Finland, Estonia, and St. Petersburg. Journal of Sex Research, 40(1), 36-49.

Haavio-Mannila, E., \& Rotkirch, A. (2000). Gender liberalisation and polarisation: Comparing sexuality in St. Petersburg, Finland and Sweden. The Finnish Review of East European Studies, 7(3-4), 4-25.

Haavio-Mannila, E., \& Rotkirch, A. (2010). Sexuality and family formation. In S. Immerfall \& G. Therborn (Eds.), Handbook of European societies (pp. 465-497). New York, NY: Springer.

Hilevych, Y., \& Sato, C. (2018). Popular medical discourses on birth control in the Soviet Union during the Cold War: Shifting responsibilities and relational values. In A.-K. Gembries, T. Theuke, \& I. Heinemann (Eds.), Children by choice (pp. 99-122). De Gruyter.

Hine, C. (2017). Ethnographies of online communities and social media: Modes, varieties, affordances. In N. G. Fielding, R. M. Lee, \& G. Blank (Eds.), The SAGE handbook of online research methods (pp. 401-415). Thousand Oaks: Sage Publications.

Hirsch, J. S. (2003). A courtship after marriage. Sexuality and love in Mexican transnational families. Berkeley, CA: University of California Press.

Ignaciuk, A. (2019). No man's land? Gendering contraception in family planning advice literature in state-socialist Poland (1950s-1980s). Social History of Medicine. https://doi.org/10.1093/shm/ hkz007.

Issoupova, O. (2012). From duty to pleasure? Motherhood in Soviet and post-Soviet Russia. In S. Ashwin (Ed.), Gender, state and society in Soviet and post-Soviet Russia (pp. 40-64). Abingdon: Routledge.

Kalmijn, M., \& Kraaykamp, G. (2018). Determinants of cultural assimilation in the second generation: A longitudinal analysis of values about marriage and sexuality among Moroccan and Turkish migrants. Journal of Ethnic and Migration Studies, 44(5), 697-717.

Kon, I. S. (2011). Tri v odnom: Seksual'naya, gendernaya i semejnaya revolutsii (Three in one: Sexual, gender and family revolutions). Sotsiologicheskie issledovaniya, 1, 51-65. (in Russian).

Kozinets, R. V. (2006). Netnography 2.0. In R. W. Belk (Ed.), Handbook of qualitative research methods in marketing (pp. 129-142). Cheltenham: Edward Elgar Publishing.

Kozinets, R. V. (2010). Netnography: Doing ethnographic research online. Thousand Oaks: Sage Publications.

Kuchma, V., \& Sokolova, S. (2017). Povedencheskie riski, opasnye dlya zdorov'ya shkol'nikov 21-go veka (Behavioral risks hazardous to the health of $21^{\text {st }}$ century schoolers). Moscow: "NMIZ zdorov'ya detej”, Minzdrav Rossii. (in Russian).

Lunin, I., Hall, T. L., Mandel, J. S., Kay, J., \& Hearst, N. (1995). Adolescent sexuality in Saint Petersburg, Russia. In AIDS. AIDS prevention research in the developing world (Vol. 9, pp. 553-560).

Mole, R. C., Gerry, C. J., Parutis, V., \& Burns, F. M. (2017). Migration and sexual resocialisation: The case of Central and East Europeans in London. East European Politics and Societies, 31(1), 201-222.

OECD.Stat. (2019). International migration database. Retrieved November 21, 2019, from https://stats .oecd.org/Index.aspx?DataSetCode=MIG\#.

Parreñas, R. (2015). Servants of globalization: Migration and domestic work. Stanford: Stanford University Press.

Qi, X. U. (2016). Migration and its impact on rural migrants' attitudes towards gender roles. Collection of Women's Studies, 6, 12.

Renzaho, A. M. N., McCabe, M., \& Sainsbury, W. J. (2011). Parenting, role reversals and the preservation of cultural values among Arabic speaking migrant families in Melbourne, Australia. International Journal of Intercultural Relations, 35(4), 416-424.

Röder, A., \& Lubbers, M. (2015). Attitudes towards homosexuality amongst recent polish migrants in western Europe: Migrant selectivity and attitude change. Journal of Ethnic and Migration Studies, 41, 1858-1884.

Rogers-Sirin, L., Ryce, P., \& Sirin, S. R. (2014). Acculturation, acculturative stress, and cultural mismatch and their influences on immigrant children and adolescents' well-being. In R. Dimitrova, M. Bender, \& F. van de Vijver (Eds.), Global perspectives on well-being in immigrant families (pp. 11-30). New York, NY: Springer. 
Rohnstock, K. (1996). Die postsozialistische Wirklichkeit ostdeutscher Frauen. In K. Starke \& K. Weller (Eds.), Leipziger Texte zur Sexualität (Vol. 7, pp. 23-36).

Rotkirch, A. (2000). The man question. Research report 1/2000. Department of Social Policy, University of Helsinki.

Rotkirch, A., \& Kesseli, K. (2010). 'The first child is the fruit of love'. On the Russian tradition of early first births. In Witnessing change in contemporary Russia (pp. 201-220).

Schnabel, S. (1991). Sex zwischen Wandel und Konstanz-Trends und Probleme des Sexualverhaltens in der DDR. In Sexualität BRD/DDR im Vergleich. Braunschweig (pp. 20-30).

Sharp, I. (2004). The sexual unification of Germany. Journal of the History of Sexuality, 13(3), 348-365.

Temkina, A. (2009). Novyj byt, seksual'naya zhizn i gendernaya revolutsiya (New life, sex life and gender revolution). Novyj byt, 6, 33-67. (in Russian).

Temkina, A., \& Zdravomyslova, E. (2015). The sexual scripts and identity of middle-class Russian women. Sexuality and Culture, 19(2), 297-320.

World Health Organization. (2007). Global strategy for the prevention and control of sexually transmitted infections: 2006-2015: Breaking the chain of transmission. Geneva: WHO Press.

Zdravomyslova, O. M. (2003). Family and society: Gender dimension of the Russian transformation. Moscow: Editorial URSS.

Zdravomyslova, O. M. (2005). Gendernoe grazhdanstvo v Sovetskoj Rossii: praktiki abortov (Gender citizenship in the Soviet Russia: practices of abortions). In Development of welfare state in the countries of Northern Europe and Russia: Comparative perspective (pp. 179-196). St. Petersburg: Skifia-Print. (in Russian).

Publisher's Note Springer Nature remains neutral with regard to jurisdictional claims in published maps and institutional affiliations. 